\title{
Assessing Mobile Learning Systems Success
}

\author{
Hsin-Hui Lin, Yi-Shun Wang, and Ci-Rong Li
}

\begin{abstract}
With the proliferation of mobile learning in educational context, measuring mobile learning system success has become an important issue for academics and practitioners. Although mobile learning has received much attention among researchers, little research has been conducted to assess the success and/or effectiveness of mobile learning systems. Thus, the main purpose of this study is to develop and validate a multi-dimensional instrument for measuring mobile learning system success (MLSS) based on previous research. This empirically validated instrument will be useful to researchers in developing and testing mobile learning system success model, as well as to educators in understanding MLSS from student perspective and promoting the use of mobile learning systems.
\end{abstract}

Index Terms-Assessment, mobile learning, systems success.

\section{INTRODUCTION}

Recently, mobile learning has become more and more important in the educational context because the rapid advance and popularity of wireless communication and mobile technologies [1]-[5]. Numerous studies about the use of mobile and wireless communication technologies in education also have been reported, and indicated that these mobile technologies can complement and add value to the existing learning models, such as the social constructive theory of learning with technology [6] and conversation theory [7]. Mobile learning originates from distance education resulting from the characteristics of mobile technology, which is the following up of e-learning. E-learning typically took learning away from the classroom, whereas mobile learning is taking learning away from a fixed location [8].

Mobile learning refers to the delivery of learning to students anytime and anywhere through the use of mobile devices (e.g., personal digital assistants, cellular phones or portable computers). With the use of mobile devices, students can interact with educational resources while away from their normal place of learning [9]-[11]. Recently, there is recognition in mobile learning studies that e-learning system using mobile devices can provide educational efficacy and improvement for students and e-learners [12], [13]. Thus, mobile learning is becoming progressively more significant, and that it will play a vital role in the rapidly growing e-learning market. While a considerable amount of research

Manuscript received November 21, 2014; revised January 23, 2015.

Hsin-Hui Lin is with the Department of Distribution Management, National Taichung University of Science and Technology, Taichung 404, Taiwan (e-mail: brenda@nutc.edu.tw).

Yi-Shun Wang is with the Department of Information Management, National Changhua University of Education, Changhua 500, Taiwan (e-mail yswang@cc.ncue.edu.tw).

Ci-Rong Li is with the Department of Management, Fuqing Branch of Fujian Normal University, China (e-mail: cirongli@gmail.com). has been conducted on mobile learning systems [14], little research has been carried out to address the conceptualization and measurement of mobile learning systems success within higher education institutions (HEIs). Therefore, methods of assessing the effectiveness of mobile learning systems are a critical issue in both practice and research. In order to address the concern, we need dependable ways to measure the success and/or effectiveness of the mobile learning system. Following the DeLone and McLean's [15] conceptual model of IS success, this study uses means of the conceptualization and empirical measurement of a mobile learning systems success (MLSS) construct to evaluate a successful mobile learning system implementation.

It is noted that the success of mobile learning systems cannot be evaluated using a single proxy construct (e.g., user satisfaction) or a single-item scale (e.g., overall success). The measure of mobile learning systems success has got to incorporate different aspects of the MLSS construct if it is to be a useful diagnostic instrument. To assess the extent and specific nature of mobile learning systems success, different dimensions of MLSS construct must be defined both conceptually and operationally. It can enable to: 1) capture multiple aspects of MLSS that may be subsumed within single scale; 2) provide insight into the nature of interrelationships among MLSS dimensions; 3) provide a more accurate diagnostic tool to assess the success of mobile learning system; 4) employ it in the post-implementation phase as an evaluation mechanism to assess whether the anticipated outcomes and benefits of mobile learning systems are realized. By using a well-validated instrument, mobile learning designers can better design and justify their activities, especially if they devote significant portion of their resources on these activities. Additionally, until such a scale is developed, the varying measures of MLSS will inhibit the generalizability and accumulation of research findings.

\section{THEORETICAL FOUNDATIONS}

Mobile learning is a specific type of e-learning through using mobile technology [1], [2]. Compared with traditional lectures, e-learning allows learners to choose (within constraints) when, where, and how they study. Through using mobile technology and devices that embrace these characteristics of portability, instant connectivity, and context sensitivity [1], mobile learning extends not only inherits advantages from e-learning, but allows learners to vary their study location and to study "on the move" through which they can experience a unique learning mode [16], [17].

Because of increasing demands on time that lead leaders to study in their lunch breaks or other free time in addition to conventional lecture theatres or the library, mobile learning system makes it easier for learners to study when and where 
they want through mobile technology and devices to transport their learning materials. Because mobile devices have become ubiquitous on college campuses, various mobile learning attempts have been applied in higher education. Advanced hardware of mobile devices (eg. camera) and various software (eg. Apps) availabilities can provide mobile learning system more capabilities to organize, manipulate and generate information for teaching and learning [18]. Today, mobile learning becomes popular with university students in America, European, and Asia. Many universities begin to provide students with construct learning management systems for $\mathrm{m}$-learning. Therefore, it is necessary to conduct research that deals with methods of assessing the effectiveness of mobile learning systems in order to be successful.

Because mobile learning system is not only a special type of e-learning but also a special type of IS, this study therefore follows on prior IS success studies to establish the theoretical foundation and conceptualization of a mobile learning systems success construct. One of the more powerful IS success model is the model argued by DeLone and McLean [19], which suggest a systematic combination of individual measures from IS success categories [20], through which facilitating to create a comprehensive measurement instrument. In the DeLone and McLean's [19] work, their comprehensive review of different IS success measures concludes with a model of interrelationships between six IS success variable categories, including system quality, information quality, IS use, user satisfaction, individual impact, and organization impact. The model makes two important contributions to the understanding of IS success. First, it provides a scheme for categorizing the multitude of IS success measures that have been used in the literature; second, it suggests a model of temporal and causal interdependencies between the categories [21], [22].

After the publication of the DeLone and McLean's [19] IS success model, researchers have begun proposing modifications to the original IS sucess model [21], [22]. Seddon [21] suggests that the inclusion of both process and causal explanations in DeLone and McLean's [19] model leads to so many potentially confusing meanings that the value of the model is diminished. He presented three distinct models intermingled in DeLone and McLean's [19] model, each reflecting a different interpretation of IS Use. The first model is a process model of IS success that describes the sequence of events relating to an IS; the second model is a representation of the behavior that manifests as a result of IS success; and the third is a variance model of IS success. Additionally, because Seddon [21] claims that IS Use is a behavior, not a success measure, he respecifies the DeLone and McLean [19] model by replacing IS use with perceived usefulness, which serves as a general perceptual measure of the net benefits of IS Use, to adapt his model to both volitional and non-volitional usage contexts.

Recently, DeLone and McLean [15] argue that Seddon's [21] reformulation of the DeLone and McLean's [19] model into two partial variance models (i.e., IS success model and partial behavioral model of IS Use) unduly complicates the success model and defeats the intent of the original model although they agree with Seddon's [21] premise that the combination of variance and process explanations of IS success in one model can be confusing. Thus, DeLone and McLean [15] present an updated IS success model by 1) using system usage or alterative "intention to use" as an important measure of IS success to adapt their model to both volitional and non-volitional usage contexts, 2) adding "service quality" measures as a new dimension of IS success model, and 3) grouping all the "impact" measures into a single impact or benefit category called "net benefit".

The updated IS success model consists of six dimensions: 1) information quality, 2) system quality, 3) service quality, 4) use/intention to use, 5) user satisfaction, and 6) net benefits. Because use is voluntary or quasivoluntary in Internet application, system usage or "intention to use" are still considered to be important measures of IS success in the updated IS success model, which also continue to be used as a dependent variable in a number of empirical studies [23], 2008). DeLone and McLean [15] suggest that their updated IS success model can be adapted to the measurement challenges of the new Internet world (eg. e-learning). Thus, this study adopted DeLone and McLean's [15] IS success model as a theoretical framework to develop an instrument for assessing the success of mobile learning systems in the high educational institutions context.

Finally, net benefits are usually proposed to serve as an ultimate IS success measure in the previous IS success models [15], [21]. However, Seddon [21] explicitly argues that different stakeholders may have different opinions as to what constitutes a benefit to them. Thus, when measuring the net benefits of an IS, researchers need to define clearly and carefully the stakeholders and context in which the net benefits are to be measured [15], [21]. Accordingly, this study focuses mainly on the perspective of the student, and uses the six updated IS success dimensions - Information Quality, System Quality, Service Quality, System Use, User Satisfaction, and Net Benefit - to develop and validate a measurement model of MLSS.

\section{RESEARCH METHODS}

\section{A. Generation of Scale Items}

Operationally, MLSS can be considered as a summation of different success measures of a mobile learning system. There are several potential measuring items for the MLSS construct. A review of the literature on IS success, IS performance, web success, e-learner satisfaction, user information satisfaction, , web user satisfaction, system use, IS service quality, web quality, and learning benefits (add references) obtained 40 items representing the six dimensions underlying the MLSS construct, and these were used to form the initial pool of items for the MLSS scale. To make sure that no important attributes or items were omitted, this study conducted experience surveys and personal interviews regarding MLSS with the assistance of two professionals, two university teachers and five mobile learning system users. They were asked to review the initial item list of the MLSS scale, and they recommended eliminating 15 items because of redundancy. After careful examination of the result of the experience surveys and interviews, the remaining 25 items were further adjusted to make their wording as precise as possible, and could be 
considered to constitute a complete scale for the MLSS measurement.

An initial MLSS instrument involving 25 items (as shown in the Appendix), with the two global measures (i.e., perceived overall performance and perceived overall success), was developed using a seven-point Likert-type scale, ranging from "strongly disagree" to "strongly agree". The global measures can be used to analyze the criterion-related validity of the instrument, and to measure the overall mobile learning systems success prior to detailed analysis. In addition to the MLSS measuring items, the questionnaire contains demographic questions.

\section{B. Sample and Procedure}

Data used to test the research model will be gathered from a sample of experienced users of mobile learning systems. Respondents will first be asked whether they have ever used mobile learning systems; if they reply in the affirmative, they will be asked to participate in the survey. The questionnaire will request the respondents to relate to the last time they used a mobile learning system and to answer the remaining questions accordingly. The respondents will then be instructed in the questionnaire to answer the questions by assessing the mobile learning system. For each question of the instrument, respondents will be asked to circle the response which best describes their level of agreement.

\section{SCAlE DEVElopment Procedure}

\section{A. Item Analysis and Reliability Estimates}

The 25-item instrument (with the two global items excluded) will be refined by analyzing the pooled data. Because the primary purpose of this study is to develop a standardized instrument with desirable psychometric properties for measuring MLSS, the pooling of the sample data is considered appropriate and justified. The first step in purifying the instrument is to calculate the coefficient alpha and the item-to-total correlations will be used to delete garbage items [24]. To avoid spurious part-whole correlation, the criterion used in this study for determining whether to delete an item is the item's corrected item-to-total correlation. An iterative sequence of computing Cronbach's alpha coefficients and item-to-total correlations will be executed for each MLSS dimension. Items with corrected item-to-total correlations below 0.4 will be eliminated.

\section{B. Identifying the Factor Structure of the MLSS Instrument}

An exploratory factor analysis will be conducted to further examine the factor structure of the instrument. Before identifying the factor structure of the MLSS construct using factor analysis, a chi-square test of Bartlett's sphericity test will be conducted, which suggests whether the intercorrelation matrix contains sufficient common variance to make factor analysis worthwhile. The sample data will be examined using a principal components factor analysis as the extraction technique, and varimax as the orthogonal rotation method. To improve the unidimensionality/convergent validity and discriminant validity [25] of the instrument through exploratory factor analysis, four commonly employed decision rules [26], [27] will be applied to identify the factors underlying the MLSS construct: 1) using a minimum eigenvalue of 1 as a cut-off value for extraction; 2) deleting items with factor loadings less than 0.5 on all factors, or greater than 0.5 on two or more factors; 3 ) a simple factor structure; and 4) exclusion of single item factors from the standpoint of parsimony.

\section{CONCLUSIONS}

Based on the previous research on IS success [15], this study has conceptually defined the domain of the MLSS construct, operationally designed the initial MLSS item list, and will empirically validate the general MLSS instrument. The proposed MLSS instrument will be of value not only to educators and systems developers responsible for the implementation and utilization of mobile learning systems, but also to researchers interested in investigating the model of mobile learning system success.

\section{APPENDIX}

Q1. The mobile learning system provides information that is exactly what you need.

Q2. The mobile learning system provides information you need at the right time.

Q3. You feel the output of the mobile learning system is reliable

Q4. The mobile learning system provides information that is easy to understand.

\section{A. System Quality}

Q5. The mobile learning system provides interactive features between users and system.

Q6. The mobile learning system is user-friendly.

Q7. The mobile learning system provides high availability.

Q8. The mobile learning system is easy to use.

Q9. The mobile learning system has attractive features to appeal to the users.

\section{B. Service Quality}

Q10. When you have a problem, the mobile learning system service shows a sincere interest in solving it.

Q11. The mobile learning system service is always willing to help you.

Q12. The mobile learning system service gives you individual attention.

Q13. The mobile learning system service understands your specific needs.

Q14. The mobile learning system staff provides high availability for consultation.

Q15. The mobile learning system provides a proper level of on-line assistance and explanation

System use

Q16. Your use the mobile learning system to record information and knowledge you learned.

Q17. You use the mobile learning system to interact with other learners.

Q18. You use the mobile learning system to share your information and knowledge. 
Q19. You depend upon the mobile learning system.

\section{User Satisfaction}

Q20. You are satisfied with this mobile learning system.

Q21. You are satisfied with the efficiency of the mobile learning system.

Q22. You are satisfied with the effectiveness of the mobile learning system.

\section{Net Benefits}

Q23. Using the mobile learning system improves my learning efficiency.

Q24. The mobile learning system helps you improve your learning performance.

Q25. The mobile learning system helps you think through learning or working problems.

\section{E. Criterion}

Q26. As a whole, the performance of the mobile learning system is good.

Q27. As a whole, the mobile learning system is successful.

\section{REFERENCES}

[1] J. Cheon, , S. Lee, S. M. Crooks, and J. Song, “An investigation of mobile learning readiness in higher education based on the theory of planned behavior," Computers \& Education, vol. 59, no. 3, pp. 1054-64, 2012

[2] C. Evans, "The effectiveness of m-learning in the form of podcast revision lectures in higher education," Computers \& Education, vol. 50, no. 2, pp. 491-98, 2008.

[3] A. Kukulska-Humle and J. Traxler, Mobile Learning: A Handbook for Educators and Trainers, London: Routledge, 2005.

[4] M. Wang and R. Shen, "Message design for mobile learning: Learning theories, human cognition and design principles," British Journal of Educational Technology, vol. 43, no. 4, pp. 561-75, 2012.

[5] R. M. Shen, M. J. Wang, W. P. Gao, D. Novak, and L. Tang, "Mobile learning in a large blended computer science classroom: System function, pedagogies, and their impact on learning," IEEE Transactions on Education, vol. 52, no. 4, pp. 538-46, 2009.

[6] A. Brown and J. Campione, "Psychological theory and design of innovative learning environments: On procedures, principles, and systems," in L. Schauble and R. Glaser (Eds.), Innovations in Learning. New Environments for Education, Mahwah, NJ: Erlbaum, 1996.

[7] G. Pask, "Minds and media in education and entertainment: Some theoretical comments illustrated by the design and operation of a system for exteriorizing and manipulating individual theses," in R. Trappl and G. Pask (Eds.), Progress in Cybernetics and System Research, Hemisphere, Washington and London, 1975.

[8] S. Y. Park, M.-W. Nam, and S.-B. Cha, "University students' behavioral intention to use mobile learning: Evaluating the technology acceptance model," British Journal of Educational Technology, vol. 43, no. 4, pp. 592-605, 2012.

[9] G.-J. Hwang and C.-C. Tsai, "Research trends in mobile and ubiquitous learning: A review of publications in selected journals from 2001 to 2010," British Journal of Educational Technology, vol. 42, no. 4, pp. 65-70, 2011

[10] J. Y. Kim, "A survey on mobile-assisted language learning," Modern English Education, vol. 7 no. 2, pp. 57-69, 2006.

[11] R. M. Shen, M. J. Wang, and X. Y. Pan, "Increasing interactivity in blended classrooms through a cutting-edge mobile learning system," British Journal of Educational Technology, vol. 39, no. 6, pp. 1073-86, 2008.

[12] H. C. Chu, G. J. Hwang, and J. C. R. Tseng, “An innovative approach for developing and employing electronic libraries to support context-aware ubiquitous learning," The Electronic Library, vol. 28 , no. 6, pp. 873-90, 2010.

[13] J. L. Shih, C. W. Chuang, and G. J. Hwang, "An inquiry-based mobile learning approach to enhancing social science learning effectiveness," Educational Technology \& Society, vol. 13, no. 4, pp. 50-62, 2010.

[14] Y.-S. Wang, M.-C. Wu, and H.-Y. Wang, "Investigating the determinants and age and gender differences in the acceptance of mobile learning," British Journal of Educational Technology, vol. 40, no. 1, pp. 92-118, 2009.

[15] W. H. DeLone and E. R. McLean, "The DeLone and McLean model of information systems success: A ten-year update," Journal of Management Information Systems, vol. 19, no. 4, pp. 9-30, 2003.

[16] J. Traxler, "Sustaining mobile learning and its institutions," International Journal of Mobile and Blended Learning, vol. 2, no. 4, pp. 58-65, 2010.

[17] S. Wang and M. Higgins, "Limitations of mobile phone learning," The JALT CALL Journal, vol. 2, no. 1, pp. 3-14, 2006.

[18] N. O. Keskin and D. Metcalf, "The current perspectives, theories and practice of mobile learning," The Turkish Online Journal of Educational Technology, vol. 10, no. 2, pp. 202-08, 2011.

[19] W. H. DeLone and E. R. McLean, "Information systems success: The quest for the dependent variable," Information Systems Research, vol. 3 , no. 1, pp. 60-95, 1992.

[20] B. L. Myers, L. A. Kappelman, and V. R. Prybutok, "A comprehensive model for assessing the quality and productivity of the information systems function: Toward a theory for information systems assessment," Information Resources Management Journal, vol. 10, no. 1, pp. 6-25, 1997.

[21] P. B. Seddon, "A respecification and extension of the DeLone and McLean model of IS success," Information Systems Research, vol. 8, no. 3, pp. 240-53, 1997.

[22] A. Rai et al., "Assesing the validity of IS success models: an empirical test and theoretical analysis," Information Systems Research, vol. 13 no. 1, pp. 50-69, 2002.

[23] Y.-S. Wang, “Assessing e-commerce systems success: A respecification and validation of the DeLone and McLean model of IS success," Information Systems Journal, vol. 18, no. 5, pp. 529-57, 2008.

[24] L. J. Cronbach, "Coefficient alpha and the internal structure of tests," Psychometrika, vol. 16, no. 13, pp. 297-334, 1951.

[25] J L. Price and C. W. Mueller, Handbook of Organizational Measurement, Marshfield, MA: Pitman Publishing, Inc., 1986.

[26] J. E. Hair, R. E. Anderson, R. L. Tatham, and W. C. Black, Multivariate Data Analysis, Upper Saddle River, NJ: Prentice-Hall, 1998.

[27] D. W. Straub, "Validating instruments in MIS research," MIS Quarterly, vol. 13, no. 2, pp. 147-69, 1989.

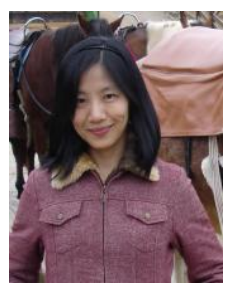

Hsin-Hui Lin is a professor in the Department of Distribution Management at National Taichung University of Science and Technology, Taiwan. She received her $\mathrm{Ph} . \mathrm{D}$. in business administration from National Taiwan University of Science and Technology. Her current research interests include electronic commerce, service marketing, and customer relationship management. Her work has been published in academic journals such as Information \& Management, International Journal of Information Management, Academy of Management Learning and Education, Computers in Human Behavior, etc.

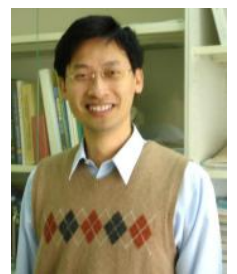

Yi-Shun Wang is a professor in the Department of Information Management at National Changhua University of Education, Taiwan. He received his $\mathrm{Ph} . \mathrm{D}$. in MIS from National Chengchi University, Taiwan. His current research interests include IT/IS adoption strategies, IS success models, customer relationship management, and e-learning. He has published in journals such as Information Systems Journal, International Journal of Information Management, Information \& Management, Government Information Quarterly, Journal of Information Science, etc. He has served as a Project Reexamination Committee Member for both research areas of Information Management and Applied Science Education in the National Science Council of Taiwan.

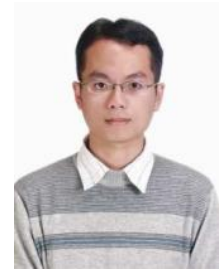

$\mathbf{C i - R o n g} \mathbf{L i}$ is an associate professor of management at Fuqing Branch of Fujian Normal University, China. He received his $\mathrm{Ph} . \mathrm{D}$. in business administration from National Dong Hwa University, Taiwan. His current research interests are focused on market orientation, product quality and innovativeness, competitive strategy and product development team. He has published in such journals as Industrial Marketing Management, European Journal of Marketing, Management Decision, and Quality \& Quantity. 